\title{
Memantine induces manic episode in a 73-year- old patient with vascular neurocognitive disorder: a case report
}

This article was published in the following Dove Press journal: Neuropsychiatric Disease and Treatment

\author{
Jinfeng Duan ${ }^{1,2}$ \\ Chengming $\mathrm{LaO}^{3,4}$ \\ Jingkai Chen ${ }^{1,2}$ \\ Fen Pan ${ }^{1,2}$ \\ Chenlin Zhang ${ }^{3}$ \\ Weijuan $\mathrm{Xu}^{1,2}$ \\ Weihua Zhou ${ }^{1,2}$ \\ Jianbo $\mathrm{Hu}^{1,2}$ \\ Desheng Shang' \\ Manli Huang ${ }^{1,2}$ \\ Yi $\mathrm{Xu}^{1,2}$
}

'Department of Psychiatry, First Affiliated Hospital, College of Medicine, Zhejiang University, The Key Laboratory of Mental Disorder's Management of Zhejiang Province, Hangzhou, People's Republic of China; ${ }^{2}$ Brain Research Institute of Zhejiang University, Hangzhou, People's Republic of China; ${ }^{3}$ College of Medicine, Zhejiang University, Hangzhou, People's Republic of China; ${ }^{4}$ Yiwu Mental Health Center, Yiwu, People's Republic of China
Correspondence: Manli Huang; Yi Xu Department of Psychiatry, First Affiliated Hospital, College of Medicine, Zhejiang University, The Key Laboratory of Mental Disorder's Management of Zhejiang Province, No 79, Qingchun Road, Hangzhou 310003, People's

Republic of China

Tel +86 57| 87235989

Fax +86 57I 87235989

Email huangmanli@zju.edu.cn; xuyizju@zju.edu.cn

\begin{abstract}
Memantine, an $N$-methyl-D-aspartate receptor antagonist, is a well-established treatment option for moderate-to-severe cognitive impairment related to Alzheimer disease. Recently, growing evidence has indicated memantine might also be effective in treatment of affective disorders. The common drug-induced adverse events of memantine include confusion, dizziness, drowsiness, headache, insomnia, and agitation. Herein, we presented a case of a 73-year-old female patient with vascular neurocognitive disorder, who developed a manic episode after taking memantine.
\end{abstract}

Keywords: memantine, depression, dementia, manic episode

\section{Introduction}

The glutamatergic system is one of the major excitatory neurotransmission systems in the central nervous system. Homeostasis in glutamate neurotransmission is fundamental for brain function. The $N$-methyl-D-asparate (NMDA) receptor plays an important role in glutamate neurotransmission. ${ }^{1}$ As a noncompetitive and low-affinity antagonist of the NMDA receptor, memantine is a well-established treatment option for moderate-tosevere cognitive impairment related to Alzheimer disease. ${ }^{2}$ In recent years, new applications of memantine has also been proposed for the treatment of acute manic episode and prevention of recurrent mood fluctuation. ${ }^{3}$ Memantine has been used as an adjuvant to treat major depressive disorder, bipolar disorder, and schizophrenia. ${ }^{4-7}$ Though the mechanisms of memantine for treating psychiatric disorders remains unclear, memantine can block the NMDA receptor competitively in the frontal cortex ${ }^{8}$ and then inhibit the function of glutamate, which further exert antidepressant effects. ${ }^{9}$ In this case study, we reported a 73-year-old woman with vascular dementia who experienced a manic episode after taking memantine. This case may help to enrich our understanding of neuropsychiatric adverse effects of memantine in elderly individuals.

\section{Case report}

A 73-year-old woman was admitted to our hospital because of deterioration of memory and abnormal behavior for more than 1 year. According to her medical records, this patient had suffered from major depressive disorder for more than 40 years and initiated antidepressive therapy 10 years before this admission. She had taken mirtazapine and olanzapine for 1 year, and her mood improved and stabilized. She gradually stopped these medications under the surveillance of her doctor. Four years before admission, the patient suffered from acute cerebral infarction, which was 
possibly caused by atrial fibrillation. Her emotional level went down after this cerebrovascular accident. She became depressed and nervous, had difficulty in falling asleep, and would complain that somebody wanted to hurt her and her family members. She felt hopeless about her life and lay in bed every day. During that period, she hardly spoke and refused to eat. She was brought to our hospital, and cranial magnetic resonance imaging (MRI, 1.5T) revealed multiple encephalomalacia in the right cerebellar hemisphere, left occipital lobe, and left pons, along with ischemic changes in the bilateral periventricular regions and bilateral centrum semiovale (Figure 1). She was then sent to our department for further treatment. On admission, she was diagnosed with depressive syndrome caused by cerebral infarction and atrial fibrillation. Quetiapine (300 mg per night) combined with venlafaxine ( $225 \mathrm{mg}$ per day) were prescribed. Her condition gradually stabilized in the following 2 months. This patient continued to take these medications, and 2 years before this admission, the dose of venlafaxine was reduced to $150 \mathrm{mg}$ per day, and quetiapine $200 \mathrm{mg}$ per night.

On this admission, the patient was well-orientated, but euphoric, childish, loss of self-insight, and abnormal behavior, such as garbage sorting and picking flowers, was observed. No hallucination or delusion was reported. Laboratory examinations, including routine blood test, biochemical profiles, tumor markers, infectious diseases, and thyroid function, were all within the normal reference ranges. Cranial MRI scanning was performed again, and the findings were similar to the previous examination (Figure 2). No acute cerebrovasuclar events were reported.

The patient scored 18/30 on the Mini-Mental State Examination, and she had graduated from a senior high school. According to the Diagnostic and Statistical Manual of Mental Disorders (fifth edition), she was diagnosed with
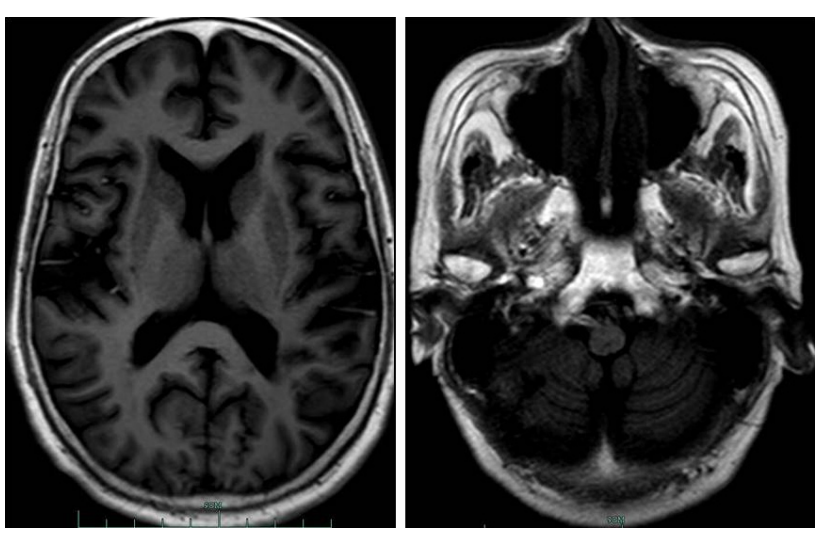

Figure I Images from the first cranial MRI scanning of our patient. Abbreviation: MRI, magnetic resonance imaging.
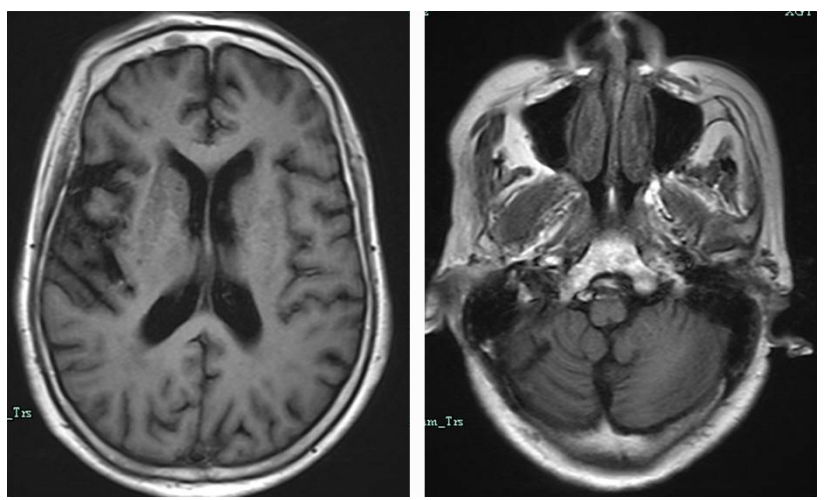

Figure 2 Images from the second cranial MRI scanning of our patient. Abbreviation: MRI, magnetic resonance imaging.

vascular neurocognitive disorder, with behavioral disturbance. Accordingly, venlafaxine was discontinued and the dose of quetiapine was increased to $400 \mathrm{mg}$ per night. Meanwhile, donepezil $5 \mathrm{mg}$ per night was also added for improving her cognitive function. However, she became emotionally unstable and fragile in the next 2 days, often crying and making noises by herself. The patient repetitively complained that she was abandoned by her children, and she would sometimes cry and sometimes smile for no reason. Escalating the dose of quetiapine to $600 \mathrm{mg}$ per night also showed no significant improvement.

Due to the poor treatment outcome, donepezil was discontinued and memantine at a dose of $10 \mathrm{mg}$ per night was initiated. Her symptoms visibly ameliorated in 2 days. However, after taking memantine for 1 week, the patient became more and more excited and talkative. She could not stop talking and repetitively sought doctors for chatting. She laughed all the time, and even began to practice Tai chi in the ward. In view of her overexcitement, memantine was stopped and lithium carbonate $300 \mathrm{mg}$ twice a day was prescribed. After ensuing the serum concentration of lithium was within the normal reference range, the dose of lithium carbonate was increased to $300 \mathrm{mg} 3$ times a day. Her emotions finally stabilized after taking lithium carbonate for 5 days.

The Institute Ethical Committee of the First Affiliated Hospital, Zhejiang University School of Medicine, approved this case study. Written informed consent for publication of this case and any accompanying image was obtained from our patient and her guardian.

\section{Discussion}

In this case study, we reported a case of a 73-year-old woman with vascular neurocognitive disorder who experienced a manic episode after taking memantine. To the best of our knowledge, this is the first report of a memantine-associated manic episode. 
Memantine is an uncompetitive, low-affinity antagonist of glutamatergic NMDA receptors that acts in a voltage-dependent pattern, which is the basis of its effect against NMDA receptor-mediated neurotoxicity. ${ }^{10,11}$ Memantine selectively bound to extrasynaptic NMDA receptors rather than synaptic NMDA receptors, thus preserving the normal synaptic activities. ${ }^{12}$ Activation of NMDA receptors could result in manic-like behaviors; thus, inhibition of these receptors was considered to have an antimanic effect. ${ }^{3}$ This was consistent with previous findings in animal models and humans that memantine has mood-stabilizing and antimanic effects. ${ }^{1,4-6}$ The mechanisms underlying these effects were hypothesized to be the antagonism of extrasynaptic NMDA receptors and preventing the sensitization of dopamine receptors. ${ }^{3,12}$

Nonetheless, previous studies also indicated the potential antidepressant effect of NMDA receptor antagonists. ${ }^{13}$ The most studied medication is ketamine, and its antidepressant efficacy is robust and rapid. ${ }^{13}$ As for memantine, two recent meta-analyses/systematic reviews revealed no favored effects versus placebo for treatment of depression in patients with unipolar or bipolar depression. ${ }^{14,15}$ These findings were consistent with an animal study that ketamine, but not memantine, had a rapid antidepressant response. ${ }^{16}$ However, there were a few studies that provided some evidences for the antidepressant role of memantine. A randomized, doubleblinded study also identified that augmentation of memantine could speed up the treatment response and lead to an early antidepressant effect in patients with bipolar depression. ${ }^{17,18}$ A case reported demonstrated that 10-week adjunctive memantine treatment significantly improved depressive symptoms, cognitive function, and life quality in a patient with bipolar depression. ${ }^{19}$ Of note, memantine could also reduce the cognitive impairment following electroconvulsive therapy. ${ }^{20}$ In addition to the glutaminergic neurotransmitter system, memantine can also act on the monoamine system and lead to antidepressant effects. ${ }^{21}$

For our patient, multiple encephalomalacia was indicated by cranial MRI scanning in the right cerebellar hemisphere, left occipital lobe, and left pons. No additional lesion was revealed in the recent MRI examination. Therefore, the manic episode was unlikely caused by these lesions. Her manic episode was just 1 week after taking memantine. According to the scale for assessing the probability of drug adverse events, a relationship between the manic episode and memantine was probable. ${ }^{22}$

To conclude, this single case report presented a memantineassociated manic episode in an elderly female patient with vascular neurocognitive disorder and recurrent depression.
Close monitoring of mood change in elderly patients with memantine treatment is necessary.

\section{Acknowledgments}

This work was supported by grant 2016YFC1306900 from the National Key Research and Development Program of China, grant LGF18H090003 of the Basic Public Welfare Research Projects in Zhejiang province, and grant $2015 \mathrm{C} 03040$ of the Key Research Project of Zhejiang Province. The funding sources had no role in the study design; collection, analysis, and interpretation of data; writing of the manuscript; or decision to submit the paper for publication.

\section{Disclosure}

The authors report no conflicts of interest in this work.

\section{References}

1. Gao Y, Payne RS, Schurr A, et al. Memantine reduces mania-like symptoms in animal models. Psychiatry Res. 2011;188(3):366-371.

2. Lipton SA. Paradigm shift in NMDA receptor antagonist drug development: molecular mechanism of uncompetitive inhibition by memantine in the treatment of Alzheimer's disease and other neurological disorders. J Alzheimers Dis. 2004;6(Suppl 6):S61-S74.

3. Serra G, Demontis F, Serra F, et al. Memantine: new prospective in bipolar disorder treatment. World J Psychiatr. 2014;4(4):80-90.

4. Serra G, De Chiara L, Koukopoulos A, Serra G. Antimanic and longlasting mood stabilizing effect of memantine in bipolar I mood disorder: two case reports. J Clin Psychopharmacol. 2013;33(5):715-717.

5. Koukopoulos A, Reginaldi D, Serra G, Koukopoulos A, Sani G, Serra G. Antimanic and mood-stabilizing effect of memantine as an augmenting agent in treatment-resistant bipolar disorder. Bipolar Disord. 2010; 12(3):348-349.

6. Demontis F, Falconi M, Canu D, Serra G. Memantine prevents "bipolarlike" behavior induced by chronic treatment with imipramine in rats. Eur J Pharmacol. 2015;752:49-54.

7. Canan F, Ataoglu A. Memantine-related psychotic symptoms in a patient with bipolar disorder. J Clin Psychiatry. 2010;71(7):957.

8. Kornhuber J, Bormann J, Retz W, Hübers M, Riederer P. Memantine displaces [3H]MK-801 at therapeutic concentrations in postmortem human frontal cortex. Eur J Pharmacol. 1989;166(3):589-590.

9. Stahl SM. Stahl's Essential Psychopharmacology. 4th edition. Cambridge, UK: Cambridge University Press; 2016.

10. Chen HS, Pellegrini JW, Aggarwal SK, et al. Open-channel block of $\mathrm{N}$-methyl-D-aspartate (NMDA) responses by memantine: therapeutic advantage against NMDA receptor-mediated neurotoxicity. J Neurosci. 1992;12(11):4427-4436.

11. Chen HS, Lipton SA. Mechanism of memantine block of NMDAactivated channels in rat retinal ganglion cells: uncompetitive antagonism. J Physiol. 1997;499(Pt 1):27-46.

12. Xia P, Chen HS, Zhang D, Lipton SA. Memantine preferentially blocks extrasynaptic over synaptic NMDA receptor currents in hippocampal autapses. J Neurosci. 2010;30(33):11246-11250.

13. Machado-Vieira R, Henter ID, Zarate CA Jr. New targets for rapid antidepressant action. Prog Neurobiol. 2017;152:21-37.

14. McCloud TL, Caddy C, Jochim J, et al. Ketamine and other glutamate receptor modulators for depression in bipolar disorder in adults. Cochrane Database Syst Rev. 2015;(9):CD011611.

15. Kishi T, Matsunaga S, Iwata N. A meta-analysis of memantine for depression. J Alzheimers Dis. 2017;57(1):113-121. 
16. Gideons ES, Kavalali ET, Monteggia LM. Mechanisms underlying differential effectiveness of memantine and ketamine in rapid antidepressant responses. Proc Natl Acad Sci U S A. 2014;111(23):8649-8654.

17. Anand A, Gunn AD, Barkay G, et al. Early antidepressant effect of memantine during augmentation of lamotrigine inadequate response in bipolar depression: a double-blind, randomized, placebo-controlled trial. Bipolar Disord. 2012;14(1):64-70.

18. Stevens J, Bies RR, Shekhar A, Anand A. Bayesian model of Hamilton Depression Rating Score (HDRS) with memantine augmentation in bipolar depression. Br J Clin Pharmacol. 2013;75(3):791-798.

19. Strzelecki D, Tabaszewska A, Barszcz Z, Józefowicz O, Kropiwnicki P, Rabe-Jabłońska J. A 10-week memantine treatment in bipolar depression: a case report. Focus on depressive symptomatology, cognitive parameters and quality of life. Psychiatry Investig. 2013;10(4): $421-424$.
20. Abbasinazari M, Adib-Eshgh L, Rostami A, Beyraghi N, Dabir S, Jafari R. Memantine in the prevention or alleviation of electroconvulsive therapy induces cognitive disorders: a placebo controlled trial. Asian J Psychiatr. 2015;15:5-9.

21. Johnson JW, Kotermanski SE. Mechanism of action of memantine. Curr Opin Pharmacol. 2006;6(1):61-67.

22. Naranjo CA, Busto U, Sellers EM, et al. A method for estimating the probability of adverse drug reactions. Clin Pharmacol Ther. 1981;30(2): 239-245.

\section{Publish your work in this journal}

Neuropsychiatric Disease and Treatment is an international, peerreviewed journal of clinical therapeutics and pharmacology focusing on concise rapid reporting of clinical or pre-clinical studies on a range of neuropsychiatric and neurological disorders. This journal is indexed on PubMed Central, the 'PsycINFO' database and CAS, and is the official journal of The International Neuropsychiatric Association (INA). The manuscript management system is completely online and includes a very quick and fair peer-review system, which is all easy to use. Visit http://www.dovepress.com/testimonials.php to read real quotes from published authors.

Submit your manuscript here: http://www.dovepress.com/neuropsychiatric-disease-and-treatment-journal 